\title{
Ashes and Their Potential in Building Industry
}

\author{
Lucia Bulíková \\ Faculty of Civil Engineering, VŠB-TU Ostrava, Ludvika Podeste 1875/17, 70833 Ostrava, Czech Republic
}

\begin{abstract}
The problem of processing, consuming and disposing of Secondary Energy Products is currently very much discussed in the construction sector. These products include ashes, scraps, and slags from the incineration of mined coal in the power industry. This article discusses the possibilities of using fly ash in road infrastructure as embankment fills or when adjusting soil properties and other use in construction industry.
\end{abstract}

\section{Secondary raw material - power ash}

The bulk of energy sources in today's society are fossil fuels, of which coal almost covers $90 \%$ of the energy demand. In addition to the large volumes of emissions, incineration at thermal power plants leads to high production of solid waste $[5,6]$.

Ashes are inorganic wastes produced by the energy industry when incinerating pulverized, finely ground coal. Fly ash consists mainly of small particles of silicate glass and is captured in the flue gas separators, which are located in the combustion plants just before the chimney discharge. Electrostatic precipitators work on an electrical principle where the ash particles are exposed to a strong electrostatic field. The charged particles are then picked up on collecting electrodes, from which they are mechanically collected and stored in the reservoir. In this way, up to $98 \%$ of the ash can be removed from the flue gases.

The raw material thus obtained can be stored in a dry state (Fig. 1) and then treated or deposited as a float ash in the tailings near its source $[1,3,5]$.

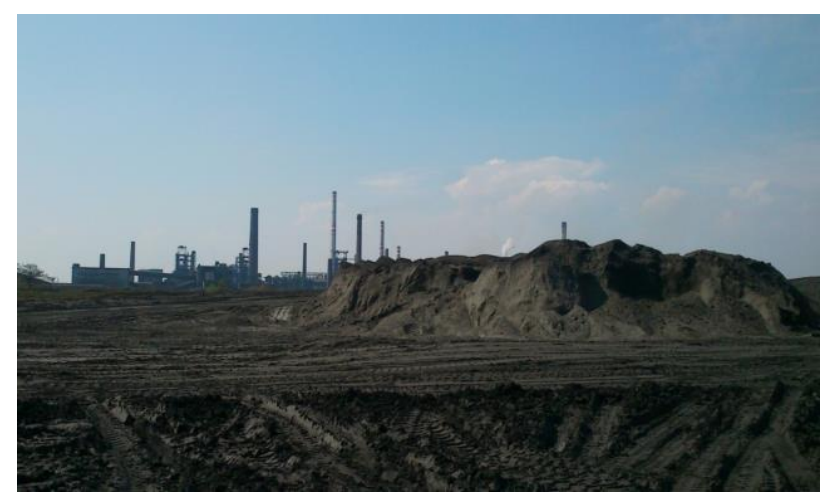

Figure 1. Dump of ash in the background with a power plant.
According to the Czech Decree on Waste, Solid Waste of Ashes is classified as Category 10 (Waste from Thermal Processes) and Subcategory $10 \quad 01$ (Wastes from Power Plants and Other Combustion Plants) as follows [5]:

\section{Ashes from coal incineration}

100103 Ashes from the incineration of peat and untreated wood

100104 Ash and dust from the combustion of petroleum products

100113 Emulgated hydrocarbon fly ash used in a fuel-equivalent manner

$1001 \quad 16$ Soil co-incineration waste containing dangerous substances

100117 Coal ash not mentioned under 100116

Domestic and foreign practice demonstrates that fresh ash is as a secondary raw material useful in different fields but is most used and applied in the field of construction. As inexpensive material, is used not only in original untreated condition but also after the subsequent treatment $[1,2,3,6]$.

The ash can be used as a mechanical treatment of soils, i.e., humidity and particle size changes as well as for soil treatment using binders according to [8] or are used as slurry according to [7] for Design and construction of road constructions using fly ashes. These regulations are valid in the Czech Republic.

One of the basic attributes considered in these materials is the ecological suitability of the ash with regard to:

- Chemical properties and heavy metal leaching 
- A limit value for the Ra226 mass activity

Ashes used in ground bodies must be registered in accordance with Regulation (EC) 1907/2006 REACH and can not be classified according to Regulation (EC) 1272/2008 - CLP (Classification, Labeling and Packaging - Classification, Labeling and Packaging of Chemicals and Mixtures).

The median value of the Ra226 mass activity can not be classified according to Decree 499/2005 Coll. of Annex 10 exceed the value of $1000 \mathrm{~Bq} \cdot \mathrm{kg}^{-1}$ for buildings with non-habitable space.

The content of organic pollutants in dry matter and the ecotoxicity of fly ash for use on roads is not assessed [7].

\section{Using ashes}

In the construction site, fly ash is used for the construction of subsoil layers, the construction of the earth body and for the treatment of underlying road surfaces (Fig. 2). They serve primarily as an alternative substitute for primary raw materials - earth, sand and gravel. More often is also used as a substitute for fine particle aggregates. Cinders also favorably affect the workability of the mixture and increase resistance to chemical effects of the environment and aggressive sulfate water. Layers made using fly ash exhibit sufficient strength and deformation properties, resistance to conveying loads and trowelling $[1,6]$.

There are many reasons to increase the usability of ashes. The most significant ones include:

- Minimizing the cost of disposal of ashes

- Reservation of a smaller liquidation area, allowing for other land use

- Financial return on sales of by-products

- Secondary products can replace scarce or expensive natural resources.

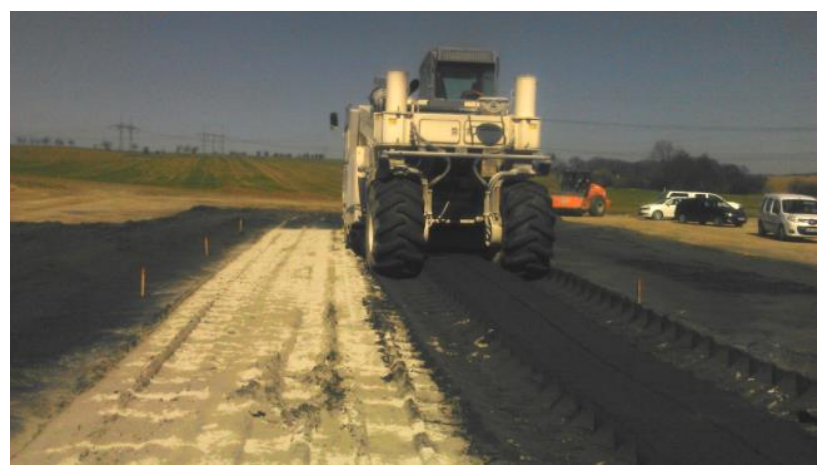

Figure 2. Mixing soil with fly ash using a ground milling machine in the field.

\section{Possibilities of fly ash for soil treatment}

Soil treatment in general is a change in soil properties in order to improve the construction performance and to use the primary potential more efficiently.
Modifications of soil properties are performed by improving the stability and accelerating of the construction on a given site.

Ashes are used in geotechnical applications associated with conveying structures $[1,3]$ :

- For increase the strength properties of soils

- For stabilization of the embankments

- For control shrinkage and swelling of soil

- For reducing the water content

The typical fly ash ratio added to the treatment is 5 to $15 \%$ with respect to soil volume. The added ratio depends on the nature of the soil, the characteristics of the particular ash and the required load capacity. To achieve a solid foundation for further construction, the soil should be compacted to its maximum bulk density. The soil water content must be regularly checked because the bulk density is primarily dependent on soil moisture. Therefore, this moisture is altered secondary, for example, it is reduced by adding ash with high calcium content, which in contrast with siliceous ash has different chemical and physical properties (Figures 3 and 4).

The variability of properties is caused by the technology of the coal firing process and the source/origin of this primary raw material. High $\mathrm{CaO}$ content results in soil desiccation and a pozzolanic reaction that stabilizes the treated soil, thereby increasing its load capacity [1].

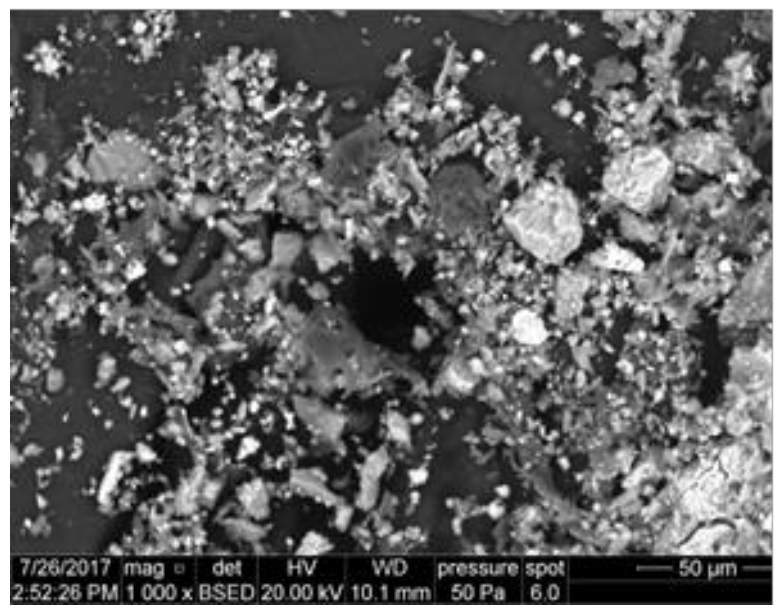

Figure 3. Irregular form of calcium ash particles.

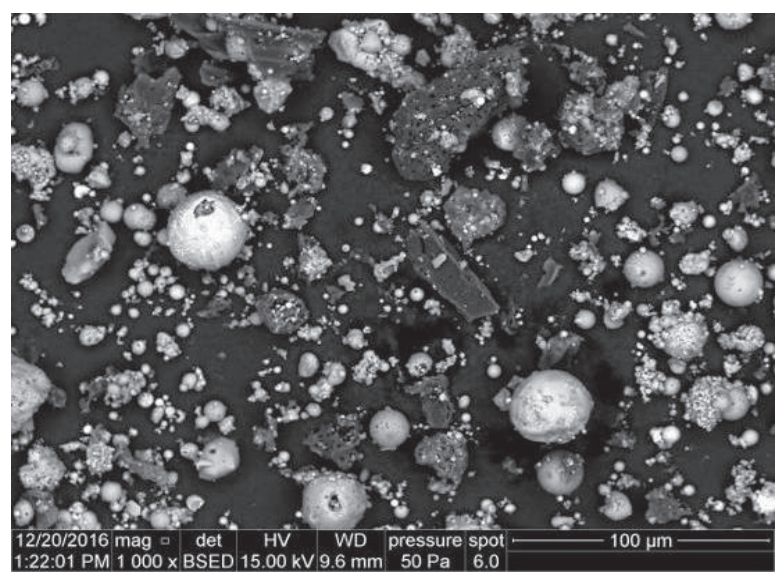


Figure 4. The spherical silica particles of fly ash.

\section{Possibilities of fly ash for building industry}

In the construction industry, for its pozzolanic properties, mainly the ash, which is generated by combustion of black and brown coal in the energy industry, is used.

Due to its favorable properties and price, fly ash is used primarily as an additive in concrete, in the production of cement as an additive to the main raw material or in the finished cement. It is also used as one of the main raw materials in the production of bricks, aerated concrete blocks and artificial aggregates, as filler for asphalt products, filling of mine works and for the production of recultivation stabilized or solidified masses.

The main components of fly ash are $\mathrm{SiO}_{2}, \mathrm{Al}_{2} \mathrm{O}_{3}$ and $\mathrm{Fe}_{2} \mathrm{O}_{3}$. We distinguish classical and fluid fly ash (Fig. 5).

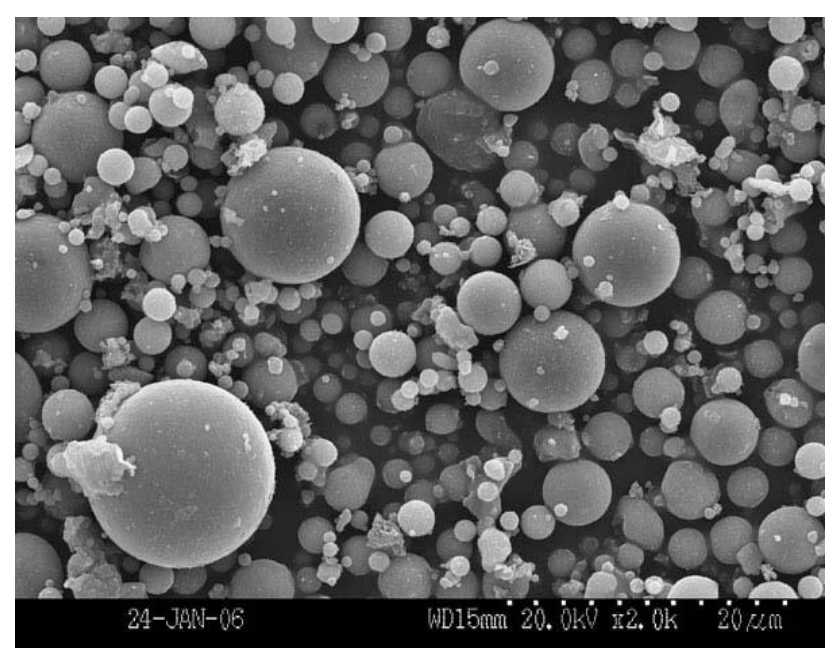

Figure 5. Brown coal fly ash.

Classical fly ashes are produced by combustion at 1400 to $1600{ }^{\circ} \mathrm{C}$ and contain more than $70 \% \mathrm{SiO}_{2}$, $\mathrm{Al}_{2} \mathrm{O}_{3}$ and $\mathrm{Fe}_{2} \mathrm{O}_{3}$, and are beta-quartz, mullite and glass phases. The proportion of this glass phase is higher than $50 \%$ and significantly affects the ash reactivity $[9,11,13]$

Fluid ash is produced by burning coal together with limestone at $850^{\circ} \mathrm{C}$. These ashes are characterized by a proportion of $\mathrm{SiO}_{2}, \mathrm{Al}_{2} \mathrm{O}_{3}$ and $\mathrm{Fe}_{2} \mathrm{O}_{3}$ in the range of $50-70 \%$ and also contain a high proportion of $\mathrm{CaO}$ in the form of a soft burnt lime, which is also reactive, and therefore these ashes are unsuitable for use in concrete. The method of combustion and the resulting ash composition affects its hydration properties, the ash content is generally less the glass phase content [9, $11,13]$.

The non-homogeneous composition is problematic for their possible further processing, which in turn determines the final properties of the prepared mixtures.
In terms of processing into building materials, the following features of fly ash are the most important:

A product of power separators

Brown and black ash,

Great variability of chemical composition,

Medium grain size 10-30 $\mu \mathrm{m}$,

Bulk density 800-1200 kg.m ${ }^{-3}$

Density 2000-2500 kg.m ${ }^{-3}$

The most important functions of ash in fresh concrete:

Improves the pumpability of concrete

Increases the resistance to bleeding of concrete

The most important Functions of ash in hardened concrete:

Increases resistance to leakage of pressurized water

Increases the compressive strength of the concrete

Improves surface quality (smoother, finer details)

In recent years, fly ash research has also focused on their possible use in alkali-activated systems. These are composites prepared by alkaline activation of latently hydrated substances or pozzolans with an alkaline activator. The activator induces the cleavage of the aluminosilicate oxides and subsequent polymerization results in new phases. At present, these systems are divided in terms of $\mathrm{CaO}$ content.

For materials with a high $\mathrm{CaO}$ content (typically blast furnace slag). During alkali activation of blast furnace slags is formed mainly C-S-H gel.

For alkali-activated masses prepared from materials with low $\mathrm{CaO}$ content (clays, fly ashes) it is assumed that the final products of so-called geopolymerization are different. Theories assume the formation of zeolite phases (Fig. 6) of the type $\left(\mathrm{Na}, \mathrm{K}_{\mathrm{n}}\left\{-(\mathrm{Si}-\mathrm{O})_{\mathrm{z}}-\mathrm{Al}-\mathrm{O}\right\}_{\mathrm{n}} \cdot \mathrm{wH}_{2} \mathrm{O}\right)$.

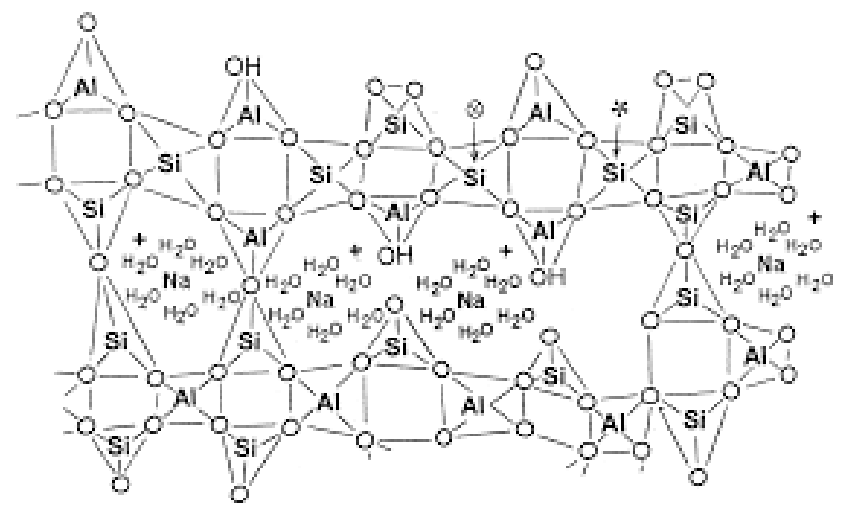

Figure 6. Structure of geopolymer [10]. 
These phases are composed of silica and aluminum tetra and octahedrons which form the so-called sialates [-Si-O-Al-O-], sialate siloxo [-Si-O-Al-O-Si-O-] and sialate disiloxo[-Si-O-Al-O-Si-O-Si-O-]. Due to the variability of the composition of the raw materials used, several different types of resulting products are formed in the geopolymer mixture [9, 10, 11, 12, 13] (Fig. 7).

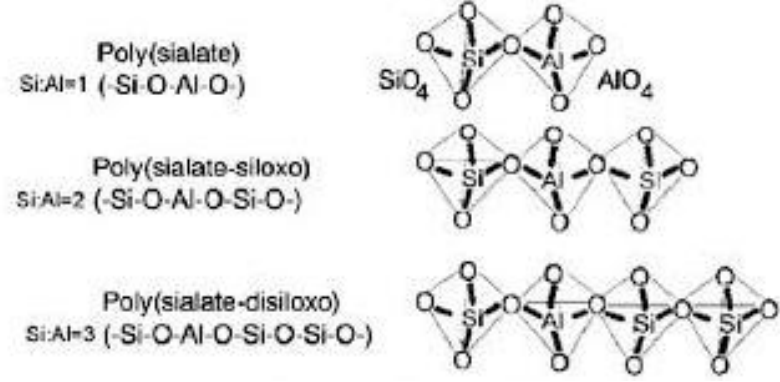

Figure 7. Structure of sialates [12].

\section{Summary}

Power ash as a cheap secondary energy product is increasingly used in the construction industry. Has a wide use and the advantage for the processors is that their production in the power industry is still rising. In the field of road construction, fly ashes are successfully used as a new construction material for the construction of embankments and as a material for soil treatment. Soil treatment serves to change the physico-mechanical properties of soils, in particular to reduce moisture, reduce plasticity and increase the bearing capacity of treated soils. Since uniformity in the quality of ash is very difficult to achieve, it is not possible to determine the generally applicable principles of their particular use. Their basic properties depend mainly on the source of the primary coal raw material, the technological process of their production and the subsequent treatment. Thus, each fly ash produced by its composition is the original and its properties and effects in practice must always be properly verified before being used in the field of construction.

Ashes are also widely used in the construction industry to prepare building materials based on Portland cement. They are used as a dopant in concrete with a positive influence on the final properties of the composite. However, a great opportunity for their application is their possible processing into alkaline activated materials. Their alkaline activation results in non-cementitious binders whose application is highly desirable mainly from an ecological point of view. The mass use of these materials in building practice will, however, be preceded by extensive laboratory research.

\section{References}

1. American Coal Ash Association: Fly ash facts for highway engineers (FHWA), pp. 47-52 (2003)

2. J. Brandštetr, J. Havlica Phase composition of solid residues of fluidized bed coal combustion, quality tests, and application possibilities. Chem. Papers 50, 4 (1996)

3. F. Kresta Secondary raw materials in transport engineering (2013)

4. R. Frýzová Phase composition of power fly ash: Quantitative determination of selected minerals (2012)

5. A. Mezencevová Possibilities of using energy fly ash Acta Montanistica Slovaca 8 (2003)

6. F. Michalíková, J. Škvarla, F. Zeleňák Properties of energy fly ash and possibilities of their utilization

7. TECHNICAL CONDITIONS TP 93, Design and construction of ash and ash roads (2011)

8. TECHNICAL CONDITIONS TP 94, Soil treatment (2013)

9. P. Mec, J. Boháčová, P. Závrský Testing of Possible Use of Fine-Grained Alkali Activated Composites in the Construction Industry. (Mat. Sc. Forum) 865 (2016)

10. J. Davidovits Geopolymer, chemistry and application. Institut Géopolymere (2008)

11. J. Bohacova, S. Stanek, P. Mec Preparation and properties of pressed metakaolin and fly ash based alkali-activated binders. (Adv. Mat. Research) 897 (2014)

12. C. Shi C., P. V. Krivenko, D. Roy, Alkaliactivated cements and concretes. Taylor\&Francis, Oxford (2006)

13. P. Mec, F. Khestl, T. Murínová, J. Boháčová Thermoanalytical study of binders containing pozzolanic and latent hydraulic materials (Adv. Mat. Research) 897 (2014)

\section{Acknowledgement}

The work was supported by means of conceptual development of science, research and innovation assigned to VŠB-TUO by the Ministry of Education, Youth and Sports of the Czech Republic. 